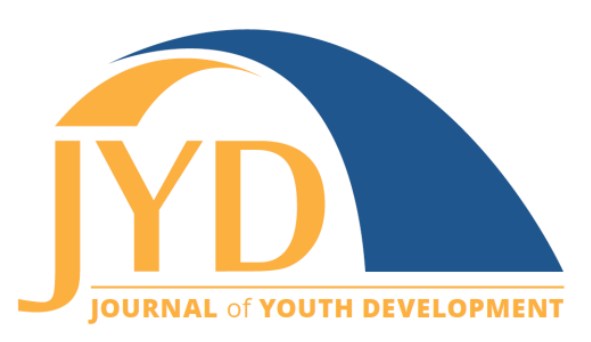

http://jyd.pitt.edu/ | Vol. 15 Issue 6 DOI 10.5195/jyd.2020.1057 | ISSN 2325-4017 (online)

\title{
From Model to Reality: The Role of Implementation Readiness
}

\author{
Deborah A. Moroney \\ American Institutes for Research \\ dmoroney@air.org
}

\begin{abstract}
Arnold and Gagnon's timely work on the 4-H Thriving Model is an excellent example of the application of developmental science in youth development practice. In their article, the authors describe how 4-H, an established youth development organization, updated the theory of change. Designing an actionable theory of change based on science is indeed a commendable effort for any youth-serving organization. However, the work does not stop there. The diverse 4-H system now has the ultimate challenge of adopting and implementing the principles presented in their theory of change. In this commentary, I discuss the often-overlooked components of implementation readiness: motivation, general capacity, and content-specific knowledge $\left(R=M C^{2}\right)$ in relation to the 4- $H$ Thriving Model. When staff are ready, they can succeed in aligning resources and coordinate professional learning for the adults, or implementers, to know and understand the theory of change and associated practices. Fostering learning and development to enact science-informed strategies, as Arnold and Gagnon have done in the 4-H Thriving Model, is critical to developing sound models of youth programming. However, to implement a model into practice, the real and human factors of implementation readiness are key to success.
\end{abstract}

Key words: positive youth development, implementation science, program readiness, capacity

\section{4-H Thriving Model}

In Arnold and Gagnon's article on the 4-H Thriving Model ("the model"), the authors describe how 4-H, an established youth development organization, endeavored to codify a new theory of change. 4-H's goals in doing so were (a) to update (and bring more consistency to) their practices in light of advances in developmental science and research on youth development practices, and (b) to bolster evaluation efforts (Arnold \& Gagnon, 2020). They created the model by building on their prior evidence-based work on the 5- or 6- $\mathrm{C}$ model (depending on

(cc) EY New articles in this journal are licensed under a Creative Commons Attribution 4.0 License. This journal is published by the University Library System, University of Pittsburgh and is cosponsored by the University of Pittsburgh Press. The Journal of Youth Development is the official peer-reviewed publication of the National Association of Extension 4-H Youth Development Professionals and the National AfterSchool Association. 


\section{The Role of Implementation Readiness}

what " $\mathrm{C}$ " camp you are in-they are competence, confidence, caring, connection, and character ... and contribution), creating a theoretical framework, and testing it.

In any situation, this is a terrific start to designing an actionable theory of change based on the science. Most youth development programs are applauded if they get this far; the process of developing a theory of change takes valuable time and resources for testing and consensus building. An even bigger challenge comes next-and this is the part of the work that ultimately impacts youth experience and outcomes. This next step is to align resources; coordinate professional learning; and get the adults, or implementers, bought in and up to speed on the theory of change and associated practices.

\section{The Challenge . . . Illustrated}

I have a now-engrained memory of 2016, a very hot day in Washington, D.C., at the National Academies of Sciences, Engineering, and Medicine Workshop on Approaches to the Development of Character. I had just finished my talk on adult capacity (Moroney, 2016), and was excited to hear a keynote by Joe Durlak (2016), one of my youth development implementation research heroes. He put up a slide that illustrated the divide between theory and practice as an actual chasm (definition: a deep fissure in the earth, rock, or another surface). I think he drew it by hand. Then he retired-so, there's that-but before that, he helped to define some critical aspects of implementation: the necessary characteristics of staff, youth, setting, and organizational capacity, including ability to deliver professional development (Durlak, 2016). So, we have some good hints about what matters for implementation, but how do we inspire a national system like $4-\mathrm{H}$ to take up a new model and implement it well?

Although I am not sure we can nonchalantly parasail over the scary chasm between theory/model and practice, I do think we have made some progress in our understanding of the first steps toward bridging this implementation chasm. I am also encouraged that Arnold and Gagnon presented the model in a way that makes it ideally suited for implementation.

In particular, I was encouraged by the model's framing as a broad umbrella—not designed to be implemented with fidelity, but a way to ensure practitioners are implementing sciencebacked strategies and a way to describe how youth programs work, with whom, and under what conditions (Arnold \& Gagnon, 2020; Bornstein, 2019). This is music to implementation scientists' ears. Not that I have a beef with fidelity; it is a terribly useful construct in researching the effectiveness of an intervention. But it is also fraught with challenges when scaling practices 


\section{The Role of Implementation Readiness}

in real-life contexts-especially contexts as varied as those of national affiliate programs like 4-H (Anyon et al., 2019). The idea that the model is intended as an umbrella rather than a prescriptive program also potentially accounts for and embraces the varied characteristics of people, experiences, settings, and organizations that Durlak (2016) touted as being key to implementation. So, we are off to a good start.

\section{Implementation Science as a Bridge}

Let's take a step back and look at the stages of implementation. These phases are adoption (do it as intended and do it well), replication (do it over and over with the same outcomes), adaptation (tweak it to suit your context while still getting the same outcomes), and a new one-which I love-reinvention (create a new and worthwhile practice) (Morel et al., 2019).

The first phase of implementation, adoption, is where issues of fidelity and quality come into play, so it's not as simple as picking up the new thing and running with it. Even before this phase, though, there is a critical first, first step: implementation readiness.

\section{Are We Ready to Implement?}

Implementation readiness helps us prepare for successful implementation of a new practice or model. Dymnicki and colleagues (2014) define implementation readiness as "the extent to which an organization is both willing and able to implement a particular practice" (p. 1). The foundation of implementation readiness is often the invisible-but-critical prerequisites that need to be in place for successful implementation. When we see disappointing findings in our evaluations of youth development programs (like lousy implementation quality or unexpected youth outcomes), we can often track it back to issues of implementation readiness. There are a lot of common-sense components of implementation readiness that have been modeled in the fields of education, healthcare, and child welfare (and fisheries management!). We are fond of one theory from the education field that frames implementation readiness as the combination of motivation, general capacity, and content-specific knowledge (Scaccia et al., 2015). Making minor adaptations to a heuristic developed by Dymnicki et al., we can express this as an equation: Readiness $=$ Motivation $\times$ General Capacity $\times$ Specific Content Knowledge. Or R $=M C^{2}$ (Get it?). Prior to implementation, we need to ensure that staff are motivated, and have the general capacity and content-specific knowledge to be successful. 


\section{The Role of Implementation Readiness}

Arnold and Gagnon's 4-H model aligns well with this equation. We will explore the model in light of these components of implementation readiness, starting with motivation.

\section{Motivation for 4-H Thriving Model}

Motivation is a combination of issues, including ownership (by key opinion leaders); overcoming innovation fatigue; and alignment to prior work, goals, or mission. The issue here is really staff buy-in, driven by the other issues. Is someone I trust championing this? Does it align with our mission as a program or organization? Is it what I signed up to do? Innovation fatigue is a big one here, especially in our field, where we are famous for the "youth work pivot" (Moroney \& Devaney, 2017). The youth work pivot is the phenomenon of expecting youth work professionals (who are experts in relationships and experts regarding the settings in which they work) to become experts in the content du jour-from prevention and life skills in the 1980s; to literacy and math in the 1990s; to science, technology engineering, and math (STEM) and social and emotional learning (SEL) in the 2000s. Thank goodness we are back to a focus on relationships and settings, guided by the rapidly developing science of learning and development (Cantor et al., 2019; Osher et al., 2019).

From Arnold and Gagnon's article, we learned the efforts Arnold and colleagues undertook to test the original model with staff and participants. Disseminating the positive results of this testing drove strong initial buy-in throughout the 4-H system-which seems critically important in a system as big and varied as $4-\mathrm{H}$. (The development of the original model is covered in a previous article; see Arnold, 2018.) Arnold and colleagues also built on or intentionally complemented existing structures and systems in 4- $\mathrm{H}$, including the $5 \mathrm{Cs}$, the Critical Elements, and Common Measures. This would help implementers see the new model as an advancement of existing work, rather than just another thing to do. Finally, Arnold and colleagues recruited ambassadors for the new model in the form of a task force of representatives from across the 4-H system. The task force effort was intensive and long-term (started in 2019, it is planned to last 3 years). The task force is explicitly focused on model-related professional development, further testing of the model, and alignment of the model with existing 4-H efforts. These activities will help raise awareness and provide opportunities for staff to weigh in on the emerging model-and in turn continue to encourage buy-in.

Not all youth development initiatives have the resources to roll out a model the way 4-H has here, but we can still learn valuable lessons from their efforts. First and foremost, ensure that the new thing, in this case a model, aligns with the goals and mission of the organization. This 


\section{The Role of Implementation Readiness}

is non-negotiable, and should be common sense, but is often steamrolled by the youth work pivot. Second, build buy-in activities into the model development process to ensure efficiency in getting that buy-in. Third, get stakeholder feedback before implementing the new thing, to hear barriers to implementation before roll-out. Finally, establish stakeholder support in some official capacity, like 4-H did with their task force, so that key opinion leaders in the organization can help spread the message about the new model and field any concerns. It is encouraging that one aim of the 4- $\mathrm{H}$ task force has been "to position the model as a continuation of the work 4-H is already doing, rather than something wholly new, and to ensure systematic, consistent adoption and use of the model across the 4-H system" (Arnold \& Gagnon, 2020, p. 12), seemingly addressing motivation explicitly. This may seem like a lot, but it is important to recognize and address these foundational and very human aspects of motivation before and during implementation. The motivation carrot may look different once implementation is underway, including things like career incentives (certifications, career pathways, recognition) and ongoing ways to ensure mission alignment and buy-in.

\section{General Capacity for the 4-H Thriving Model}

Next, let's look at general capacity. General capacity is the time, resources, space, and people required to implement the new thing. If staff are struggling with basic program execution because of challenges in this arena, then it is really difficult to add implementing something new-and this in turn affects motivation. (The components of readiness aren't quite as linear as the formula $\mathrm{R}=\mathrm{MC} \mathrm{C}^{2}$ suggests.)

4-H is a well-supported-if a little complicated in its structure-organization at the local, state, and federal levels. General capacity should not be discounted, however, as an important prerequisite to implementation of the model. In fact, the vast diversity of programs should be taken into account in considering 4-H's general capacity to implement the model. Simply, it would be easier to prepare for and implement a new thing in a smaller, more homogeneous system. For example, the task of preparing local 4- $\mathrm{H}$ leadership for implementation will be significant. The task force is a good start, but likely just that. Arnold and Gagnon underline this challenge in the article: "Establishing agreement among stakeholders to the priorities for the 4-H system is a daunting undertaking, but one that must be accomplished to ensure coherency of the 4-H experience for all youth" (p. 17).

It is impossible to write about general capacity in late 2020 without addressing the issues posed by the COVID-19 pandemic. Across the United States, youth development organizations are 


\section{The Role of Implementation Readiness}

heroically responding to the needs of youth and families during school closures, while also having to shut down program sites and furlough staff in unprecedented numbers (Afterschool Alliance, 2020). They are worried about their participants while also facing serious concerns about the longevity of their organizations. Youth development leaders are looking at this as a time to step up and ensure we don't lose a generation of young people. Youth development programs are bending over backwards to provide connections and creative supports, while also dealing with practical challenges of PPE, social distancing, and staffing. Long story short, while increased youth needs say we should be doubling down on new ways/models to promote thriving, everything we know about implementing something new while systems are in total chaos signals that we should not. There is no right answer here. It's messy right now, and organizations like 4- $\mathrm{H}$ are doing what they can to ensure their participants are cared for and thriving, despite serious challenges to general capacity (4- $\mathrm{H}, 2020)$. But we, as researchers, may need to be a little forgiving about what this year looks like from an implementation science perspective. And youth development supporters, funders, and stakeholders may need to manage expectations about rolling out the new thing while general operations feel like they are being held together by duct tape and safety pins. This is a not a specific crux of the wellsupported 4-H system but of the youth development field more broadly, which is asked to do a lot for a little even in the best of times (Ham, 2020).

\section{Content-Specific Knowledge for the 4-H Thriving Model}

Content-specific knowledge is the skills, practices, resources, and competencies to implement the new thing. Content-specific knowledge is often shared through professional learning opportunities, toolkits, and on-the-job learning. Note that this is the last interrelated component of implementation readiness but often where we begin as a field. Think about the SEL movement. Many of us started by hosting and attending SEL professional development and by creating or adopting SEL programs, activities, and measures(!?)—but did we take a step back and ask, are staff ready for this? Do they think it is a good idea? Will someone own this work? Are they exhausted from the STEM work we just completed? Can I even deal with this right now when we don't even have resources in place for snacks? Again, the components of readiness are interrelated, because learning about the new thing can be motivating, can help us see value in our current practices, and can even build capacity in some cases. So, it doesn't have to be last, but its position as the last component of the $\mathrm{R}=\mathrm{MC}^{2}$ equation highlights the fact that it is probably not the first thing we should do. 


\section{The Role of Implementation Readiness}

Arnold and colleagues had some lessons learned from their work on the Five (or Six) Cs that emboldened them to come up with an ambitious plan to disseminate content-specific knowledge. The 4-H professional development plan to disseminate the model described in Arnold and Gagnon's article is enviable from any vantage point. Internal systemic professional development in our field is typical only in the large, federated organizations like 4-H and the YMCA or in city intermediaries and state afterschool networks. In other cases, national conferences and conventions, like National Afterschool Association, BOOST, and Beyond School Hours, help to bolster and spread new content-specific knowledge, but none do so as systematically as can be done through a sequenced and scaffolded learning experience with internal program experts and amongst peers as $4-\mathrm{H}$ has proposed.

We will watch with interest and wish 4-H all the best in their endeavor to build content-specific knowledge on the model within their system, in the context of the other components of readiness, including the pandemic - which is making everyday implementation tricky, let alone trying to scale something new. But in this case the something new is non-negotiable: to ensure all young people have opportunities to thrive (Darling-Hammond, 2019).

\section{Ready to Thrive?}

The 4-H Thriving Model is built on a rich body of knowledge on after-school programming, on an impressive portfolio of research on $4-\mathrm{H}$, and on new consensus findings from the science of learning and development (sometimes called SoLD; Lerner \& Lerner, 2013; Cantor et al., 2019; Moroney \& Young, 2019; Osher et al., 2019; Osher et al., 2020). The findings from the science of learning and development tell us that all young people have potential to thrive, and that development is individual, malleable, and influenced primarily by developmentally rich relationships and identity-safe settings (Cantor et al., 2019; Osher et al., 2019). After-school programs and systems like 4- $\mathrm{H}$ are ideally suited to fostering learning and development and have a responsibility to provide transformative learning opportunities in settings that are not just equitable but robust (Moroney \& Young, 2019; Osher et al., 2020).

4-H's implementation of SoLD-aligned practices will further our understanding of the unique and combined contribution of youth development programs to learning and development, in conjunction with other youth-serving systems.

It is imperative that youth development programs and systems like 4- $\mathrm{H}$ foster learning and development to enact science-informed strategies. But to get successfully from model (i.e., 
Journal of Youth Development | http://jyd.pitt.edu/ | Vol. 15 Issue 6 DOI 10.5195/jyd.2020.1057

The Role of Implementation Readiness

science, research, theory) to practice, we must set the adults up for success by attending to the real and human factors of implementation readiness-it is implementation readiness that allows us to cross the chasm and to actualize the great responsibility we have in fostering optimal learning and development towards thriving.

\section{Acknowledgement}

The author would like to acknowledge the generous review and contributions offered by Phil Esra and Jill Young.

\section{References}

Afterschool Alliance. (2020). Afterschool Alliance COVID-19 tracking program provider survey. Afterschool Alliance. http://www.afterschoolalliance.org/documents/Afterschool-COVID-19-Wave-1-Wave-2Provider-Comparison-Toplines.pdf

Anyon, Y., Roscoe, J., Bender, K., Kennedy, H., Dechats, J., Begun, S., \& Gallger, C. (2019). Reconciling adaption and fidelity: Implications for scaling up high quality youth programs. Journal of Primary Prevention. https://doi.org/10.1007/s10935-019-00535-6

Arnold, M. E. (2018). From context to outcomes: A thriving model for 4-H youth development programs. Journal of Human Sciences and Extension, 6(1), 141-160.

Arnold, M. E., \& Gagnon, R. J. (2020). Positive youth development theory in practice: An update on the 4-H Thriving Model. Journal of Youth Development 15(6), 1-23. https://doi.org/10.5195/jyd.2020.954

Bornstein, M. H. (2019). Fostering optimal development and averting detrimental development: Prescriptions, proscriptions and specificity. Journal of Applied Developmental Science, 23(4), 340-345.

Cantor, P., Osher, D., Berg, J., Steyer, L., \& Rose, T. (2019). Malleability, plasticity, and individuality: How children learn and develop in context. Applied Developmental Science, 23(4), 307-337. https://doi.org/10.1080/10888691.2017.1398649

Darling-Hammond, L., Flook, L., Cook-Harvey, C., Barron, B., \& Osher, D. (2019). Implications for educational practice of the science of learning and development. Applied Developmental Science, 24(2), 97-140. https://doi.org/10.1080/10888691.2018.1537791

Durlak, J. (2016). What you HAVE to know about program implementation. Paper presented at the National Academies of Sciences, Engineering, and Medicine Workshop on Approaches to the Development of Character, Washington, D.C. 
Journal of Youth Development | http://jyd.pitt.edu/ | Vol. 15 Issue 6 DOI 10.5195/jyd.2020.1057

The Role of Implementation Readiness

Dymnicki, A., Wandersman, A., Osher, D., Grigorescu, V., \& Huang, L. (2014). Willing, able $\rightarrow$ ready: Basics and policy implications of readiness as a key component for implementation of evidencebased interventions. Executive summary. https://youth.gov/docs/Readiness IssueBrief 508.pdf

4-H. (2020). 4-H at home. 4-H. https://4-h.org/about/4-h-at-home/

Ham, H. (2020). Skilled professionals, not superheroes. National Afterschool Association. https://naaweb.org/professional-development/item/1342-skilled-professionals-not-superheroes

Lerner, R. M., \& Lerner, J. V. (2013). The Positive development of youth: Comprehensive findings from the 4-H study of positive youth development. Institute for Applied Research in Youth Development at Tufts University. https://4-h.org/wp-content/uploads/2016/02/4-H-Study-ofPositive-Youth-Development-Full-Report.pdf

Morel, R. P., Coburn, C., Catterson, A. K., \& Higgs, J. (2019). The multiple meanings of scale: Implications for researchers and practitioners. Educational Researcher, 48(6), 369-377.

Moroney, D. (2016). Ready to implement? How the out-of-school time workforce can support character development through social and emotional learning: A review of the literature and future directions. Paper presented at the National Academies of Sciences, Engineering, and Medicine Workshop on Approaches to the Development of Character, Washington, D.C.

Moroney, D., \& Devaney, E. (2017). Ready to implement? How the out-of-school time workforce can support character development through social and emotional learning: A review of the literature and future directions. Journal of Character Education, 13(1), 67-89.

Moroney, D., \& Young, J. (2019). The science of learning and development in afterschool settings and systems. American Institutes for Research.

Osher, D., Cantor, P., Berg, J., Steyer, L., \& Rose, T. (2019). Drivers of human development: How relationships and context shape learning and development. Applied Developmental Science, 24(1), 6-36. https://doi.org/10.1080/10888691.2017.1398650

Osher, D., Pittman, K., Young, J., Smith, H., Moroney, D., \& Irby, M. (2020). Thriving, robust equity, and transformative learning \& development: A more powerful conceptualization of the contributors to youth success. Forum for Youth Investment.

Scaccia, J. P., Cook, B. S., Lamont, A., Wandersman, A., Castellow, J., Katz, J., \& Beidas, R. (2015). A practical implementation science heuristic for organizational readiness: $\mathrm{R}=\mathrm{MC}^{2}$. Journal of Community Psychology, 43(4), 484-501. 